\title{
Hot embossing of polypropylene micro-tubes into functional tubular components with controlled inner-pore sizes
}

\author{
Jie Zhao ${ }^{1, *}$ and $Y i$ Qin ${ }^{1}$ \\ ${ }^{1}$ Centre for Precision Manufacturing, Department of Design, Manufacture and Engineering Management, The University of Strathclyde, \\ Glasgow G1 1XJ, United Kingdom
}

\begin{abstract}
To meet ever-increasing demands on the micro-components for medical and non-medical applications, a new micro-shaping technology - "hot embossing of micro-tubes", had been developed for the forming of polymeric tubular micro-components. The paper presents the results from the forming of Polypropylene(PP) micro-tubes with outer diameters of $1.3 \mathrm{~mm}$ and inner diameters $0.6 \mathrm{~mm}$, to achieve various reduced inner-features. The study was effected by combining experiment, numerical simulation and SEM analysis. FE simulation was implemented by using the material data obtained from the material characterisation tests. The forming experiment was conducted with a high-precision hot-embossing machine, developed in-house, with automated handling and good reliability and repeatability. The Polypropylene (PP) micro-tubes were successfully formed into the desired features at the temperatures of $60^{\circ} \mathrm{C}$ and $100^{\circ} \mathrm{C}$ respectively. The influences of the parameters/factors, such as tool design, temperature, forming pressure and holding time, on the quality of the shaped parts, are discussed in details. Based on this study, it is concluded that PP is an ideal candidate material among the polymeric materials for hot embossing of tubular microcomponents, due to its good ductility, low transition temperature and low viscosity. Keywords: Micro forming, Manufacturing process, Tool geometry
\end{abstract}

\section{Introduction}

Technical and market demands of tubular microcomponents have led to the development of a hot embossing process and corresponding machine for forming polymeric micro-tubes. Those micro-tubular components are usually with outer diameter of $2 \mathrm{~mm}$ or below and are designed with various shapes and different features, such as needles, balloons, multi-faceted, closed and open ended at the tips, with a range of plastic materials, and are being employed in various areas, for instance, micro-fluidic devices, drug delivery system, laboratory analysis equipment, and micro-fluidic system [1]. Due to the fact that most of these kinds of components are disposable, cost effectiveness is one important factor for the process development and evaluation. However, the current manufacturing technology is not yet satisfying the demand for economical mass-production of tubular micro-component with reduced inner channel dimension. Injection moulding is one of the most widely used process for polymer tubular component forming, which makes the complex and intricate shaping possible. However, injection moulding includes expensive production line and a high cost for the mould making it only economical for very large production quantities.

An innovative hot embossing process and machine for polymeric micro-tubular component forming have been developed in the recent years and demonstrated a great potential [2-4] in the technical and economical aspects, including the advantages of lower forming temperature, reduced system complexity, shorter production cycle time, quicker die changeover and more cost efficiency compared to other replication processes.

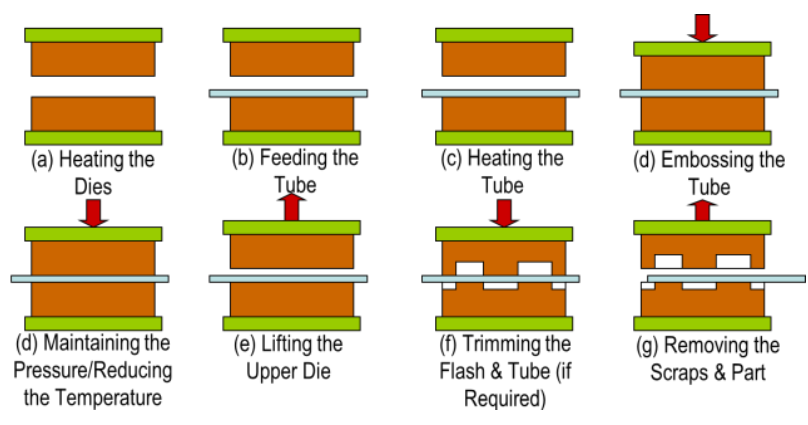

Fig. 1. Polymeric micro-tube hot embossing forming process chain.

With some variations from the conventional hot embossing process, the processing sequence of forming micro-tubes is as shown in Fig. 1: (a) the tool-set would be heated to the required temperature; (b) the tube would be fed into the lower shaping die; (c) the tube would be heated rapidly by contact with the die due to the small volume of the material involved; (d) the lower die would secure the tube properly while it is embossed by the upper tool. A proper pressure would be maintained for a specific time to allow shape-setting and fusion-bonding at the inner folded-interfaces. At this stage, to maintain shape

\footnotetext{
Corresponding author: j.zhao@strath.ac.uk
} 
stability, a cooling mechanism could be necessary; (e). the upper-tool would then be lifted; (f). the flash formed may also be trimmed off by a following shaving process; and (g). the scrap and shaped part are removed from the lowerdie.

The aim of the research reported in this paper is to conduct a comprehensive study on the influences of tool and process factors on the quality of the parts formed with a view to generating a design and manufacture control guideline for this forming technology. The forming principle was investigated by a combination of experimental and numerical approaches. The hot embossing micro-tube process was analysed by focusing on the central-pore forming, the cavity filling and monitoring the transformation of stress, strain and material flow. The in-depth studying of forming result and discussion on its influential factors enhances the understanding of hot embossing micro-tubular component and quality control.

\section{PP micro-tube}

Polypropylene, acronym PP, is one common polymer with versatile applications. $\mathrm{PP}$ has melting temperature of around $150^{\circ} \mathrm{C}$, which makes it beneficial for almost all thermal plastic forming process, including hot embossing. Its good ductility and low viscosity also make it suitable for hot embossing process. Besides, another benefit of the PP material is the low material cost compared to other engineering polymers. The original PP tube (Fig. 2) has an outer diameter of $1.3 \mathrm{~mm}$ and an inner diameter of $0.6 \mathrm{~mm}$.

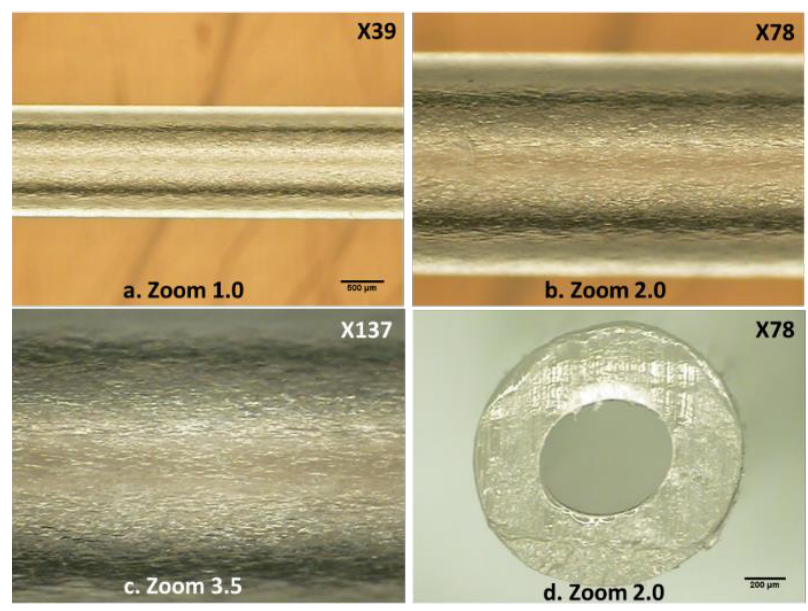

Fig. 2. Original PP tube, a-c) longitudinal tube direction, d) circular cross-section of the tube.

\section{FE Simulation}

FE simulation of the hot embossing micro-tubes is aiming to examine the shaping capability of the proposed process and in-depth understanding of the forming mechanism, the flow behaviour and its influential parameters. The valid model can also be used to predict the forming result in order to save the time and cost from the experiment.
The simulation was conducted with a commercial FE software DEFORM-3D ${ }^{\mathrm{TM}}$ by SFTC. The general setup of the simulation can be seen in Fig. 3. The simulation contains top and bottom dies, with the micro-tube set as the workpiece located between both dies. The die cavities for both top and bottom dies are one variable parameter for this study. The top and bottom dies were set as rigid bodies. The micro-tube is set as an elasto-plastic model. The tube elements are treated as elastic until the yield point is reached. After this point, any portions of the elements that reach the yield point are treated as plastic, while the remainder of the element is treated as elastic.

The plasticity model is defined by the flow stress as shown in equation (1), which represents the flow stress behaviour of polymer micro-tube, where the stress $(\bar{\sigma})$ is dependent on strain $(\bar{\varepsilon})$, strain rate $(\dot{\bar{\varepsilon}})$ and temperature (T).

$$
\bar{\sigma}=\bar{\sigma}(\bar{\varepsilon}, \dot{\bar{\varepsilon}}, T)
$$

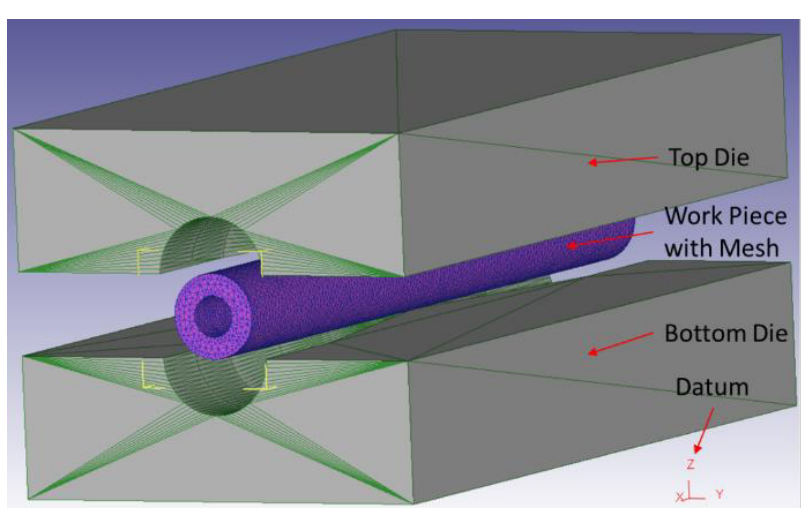

Fig. 3. Hot embossing polypropylene micro-tube simulation setup.

In the DEFORM software, a user defined material model was created with the material properties shown in Table 1. The key mechanical and thermal properties such as the temperature and strain rate dependent flow stress were obtained from the material characterisation tests of the micro-tube used in experiment. The Young's Modulus was calculated according to the different temperatures and applied in the simulation.

Table 1. Material properties for PP micro-tube.

\begin{tabular}{|c|c|}
\hline Property & Value \\
\hline Density $\left[\mathrm{g} / \mathrm{cm}^{3}\right]$ & 0.9 \\
\hline Poisson's ratio [-] & 0.42 \\
\hline Thermal expansion $\left[\mu \mathrm{m} / \mathrm{m}-{ }^{\circ} \mathrm{C}\right]$ & $100-180$ \\
\hline Thermal Conductivity $[\mathrm{W} / \mathrm{m}-\mathrm{K}]$ & 0.15 \\
\hline Specific Heat Capacity $\left[\mathrm{J} / \mathrm{g}-{ }^{\circ} \mathrm{C}\right]$ & 1.8 \\
\hline Heat transfer Coefficient $[\mathrm{W} / \mathrm{m} 2 \mathrm{~K}]$ & 24.5 \\
\hline Friction Coefficient $[-]$ & 0.1 \\
\hline
\end{tabular}


The boundary condition was set as an interaction between the work piece and the dies and a "self-contact" relationship to simulate the bonding of the tube inner surface caused by temperature and pressure during the forming process. This interaction is dominated by the friction and heat transfer, however the heat transfer to the dies was not considered to reduce calculation time, but the change of heat within the work piece was calculated. The values of friction coefficient and heat transfer can also be found in Table 1. Additionally, heat exchange with the environment was considered to simulate the cooling effect of the area on the work piece which are not in contact with the dies. The analysing temperature of work piece and the dies were set according to the experimental setup.

The vertical movement is set for the top die to the $-Y$ direction with a defined velocity. The velocity is a variable, which has been identified as one of influential forming parameters. The displacement of the top die leads to a moulding pressure of the polymer tube and forces the polymer flows into the die cavity and spread around during the embossing process.

\section{Experiment}

Forming experiments were conducted by adopting the high precision and fully automatic hot embossing machine developed in-house (Fig. 4), in order to gain a substantial understanding of the hot embossing microtube forming process, as well to determine the key forming parameters and their influence to the process result. Each micro-tube was cut to $50 \mathrm{~mm}$ in length, picked up by a handling device into the machine and formed with pre-set forming parameters, such as temperature, force and holding time.

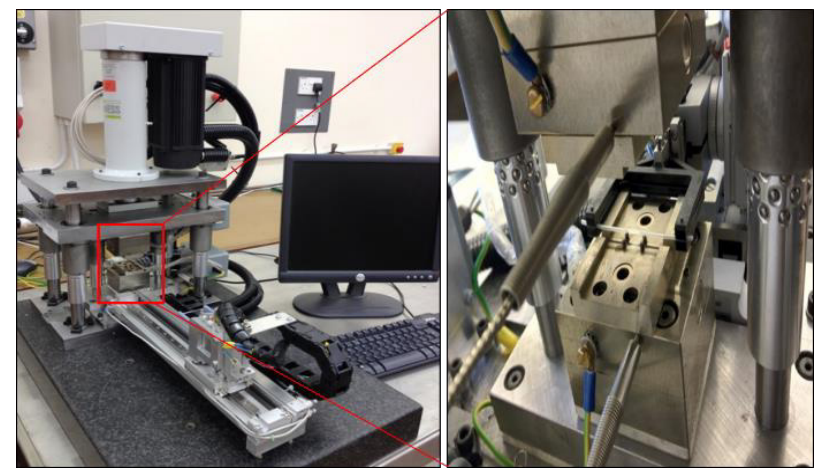

Fig. 4. The micro-tube hot embossing machine system (left) and forming tool (right).

Fig. 5. shows the SEM images of PP tube formed under $60^{\circ} \mathrm{C}$, with different magnitudes. The formed tube exhibits smoothly-formed edges on the top right image. The inner pore measurement is $480 \mu \mathrm{m}$ in its width and $164 \mu \mathrm{m}$ in its height. A good fusion bonding result can be observed; where the inner surface line disappeared and the material shows a homogeneous appearance near the bonding area.

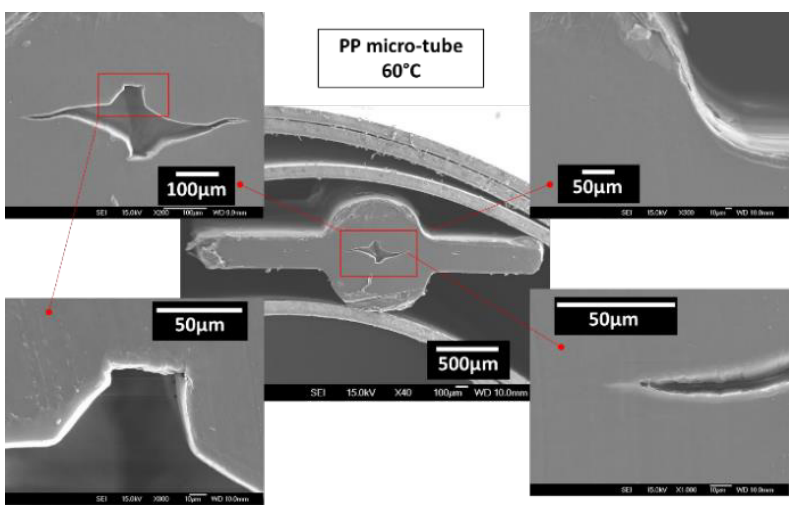

Fig. 5. The SEM images of PP tube formed under $60^{\circ} \mathrm{C}$.

\section{Result and Discussion}

Generally, hot embossing is commonly used in precise and qualitative manufacture, for replication of microfeature from the forming die to a flat surface [5]. Even though many process variations have been developed over the recent years, the application on direct form 3D features (both outer and inner features) on micro-tubes needs further investigation due to more dedicated tooldesign and process control are required. In order to achieve a controllable pore-shape and dimensions at the inner area of the tubes, the forming parameters need to be properly considered.

\subsection{The geometries formed}

The results obtained on micro-tube forming under same experimental and simulated conditions were compared in order to validate the simulation model. As shown in Fig. 6, six geometrical measurements are taken from two samples, from both experimental and simulation results. From the comparison it can be seen, there is minor deviation of the outer dimension of the tube between the experiment and simulation. However, the rest of the dimensions are very similar, especially the ratio of vertical and horizontal direction for the formed inner pore $\left(\mathrm{H}_{\mathrm{i}} / \mathrm{W}_{\mathrm{i}}\right)$ and the height of the tube material fill into the die cavity $\left(\mathrm{H}_{\mathrm{f}}\right)$. It shows that the numerical model can predict the trend of the hot embossing process and can be used to assist in the further forming research.

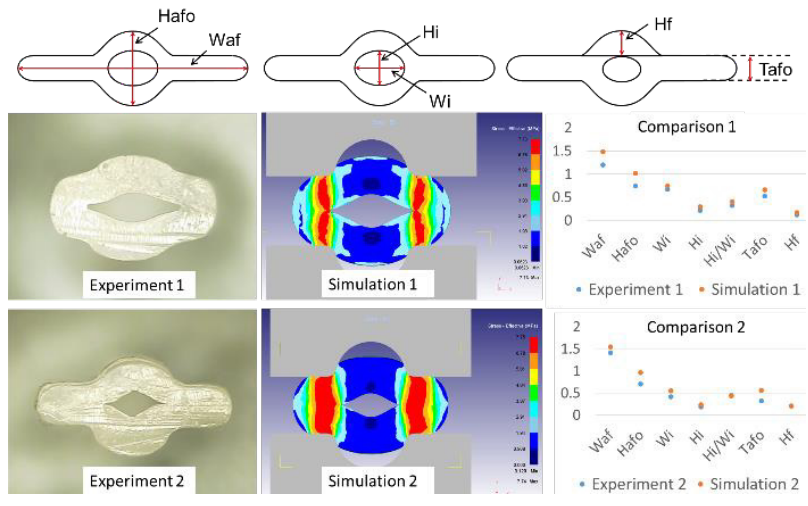

Fig. 6. Geometrical comparison of the experiment and simulation result. 


\subsection{The die cavity}

Unlike the conventional 2D hot embossing on a foil or plate, where the high quality product refers to exact replication of the micro-structure from the die to the polymer, the micro-tube forming is not a process to "print" the concave cavity on the polymer directly. It is a dynamic transformation process, which assists the tube transferring into different geometry from its original size. The geometry of the tube, such as the inner pore size and aspect ratio is changing along with time. It means that, if the top die stroke moving distance and speed are well controlled, different forming results can be achieved with the same micro-tube and die setup.

The die cavity has the most direct impact on the forming result. In order to effectively study the design of die cavity, the micro-forming die has been configured as shown in the Fig.7. The cavity includes three geometrical variations as $R_{c}, R_{f}$ and $h$, which represent the radius of the die cavity, the radius of the die fillet and the offset of the circle centre respectively.

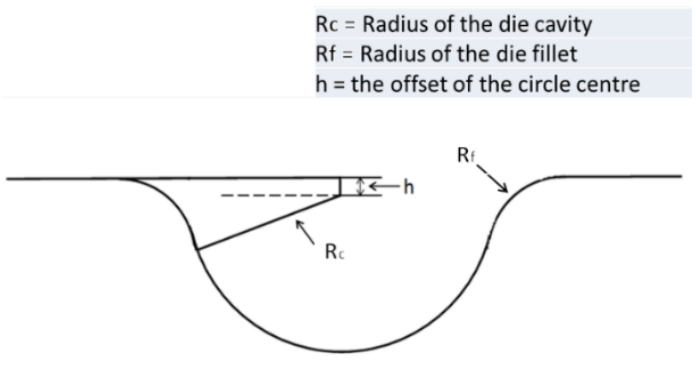

Fig. 7. Hot embossing die cavity configuration with three geometrical variations.

\subsubsection{The parameter $R_{c}$}

A series of simulations with different die cavity configurations are shown in Fig.8. to study the influence of $R_{c}$ on the forming result.

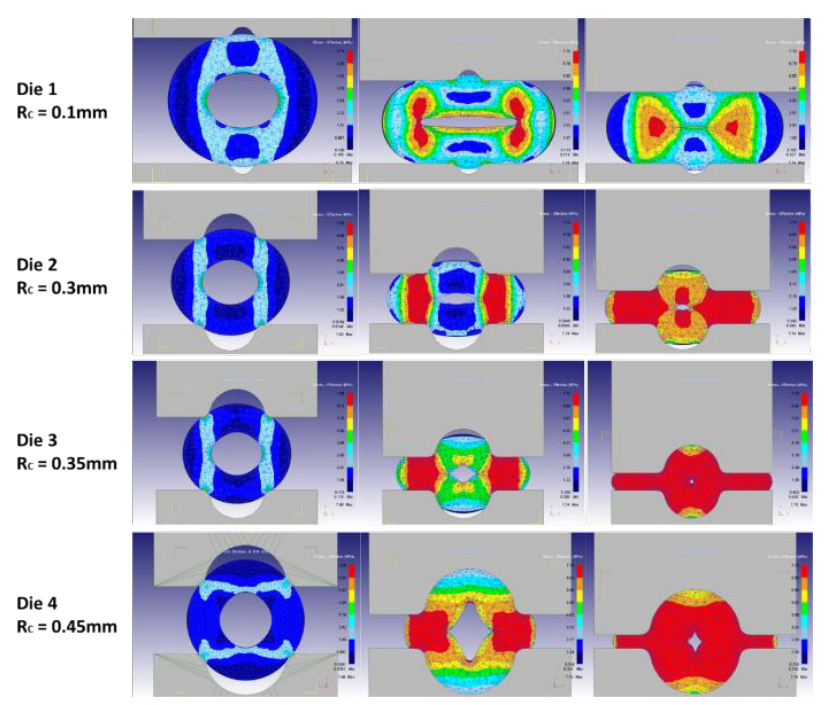

Fig. 8. Illustration of influences on the pore-formation from the die-cavity geometry (PP tube formed under $100^{\circ} \mathrm{C}$ ).
Employing the same PP micro-tube and by changing $R_{c}$ (radius of die cavity), the formed tubes exhibit large variations in geometry, especially the inner pore size. It can be explained that by controlling the ratio of the material flow in the vertical direction (the direction of the tool-movement) and the transversal direction, it is possible to control the height to the width ratio of the formed central pore as well as its transitional shape of the pore edges. Die 1 for instance, since the die cavity is much smaller than tube diameter, the surface tension generates high resistance force to prevent material flow into the hollow cavity. However, the increase of cavity size from Die 2 to 4 leads to a better material 'filling' into the cavity. It is evident that the geometry of die design has a strong impact to the formed components. In other words, controlling the shape and size of the central pore is possible by controlling the die cavity shape and dimensions properly. In order to further understand the effect of the die cavity geometry $R_{c}$ on the formation of tube inner pore, the dynamic transformation process of micro-tube inner pore along with the movement of top die has been presented in Fig.9.

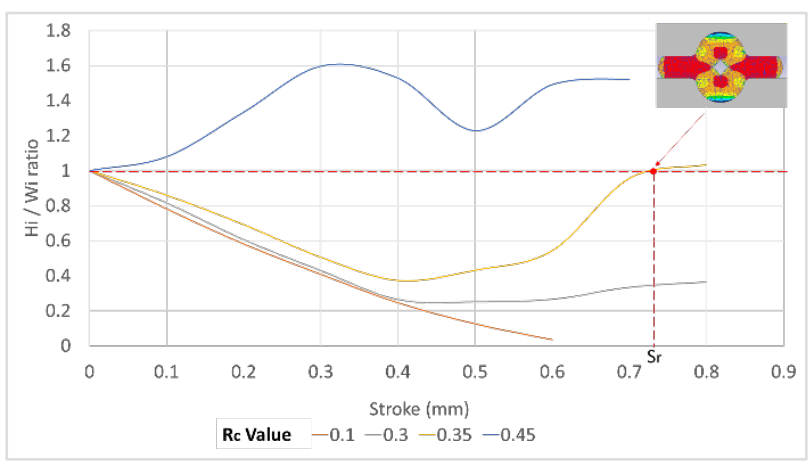

Fig. 9. Simulation result of $\mathrm{PP}$ tube under $100^{\circ} \mathrm{C}$ (change of $R_{c}$ ).

Along with the movement of the top die stroke, the ratio of $\mathrm{H}_{\mathrm{i}} / \mathrm{W}_{\mathrm{i}}$ reflects the shape of the inner pore at a different stage, in order to find out which transitional direction is dominant to the inner pore forming. Considering the $\mathrm{H}_{\mathrm{i}} / \mathrm{W}_{\mathrm{i}}$ ratio for original tube is 1 , if the ratio is reducing from 1 to the direction of 0 , means the pore is becoming flat in horizontal direction; on the other hand, if the ratio is increasing from 1 to the direction of 2 , means the pore is stretched in the vertical direction. The $\mathrm{S}_{\mathrm{r}}$ in the graph represents the point of top die stroke when the ratio of $\mathrm{H}_{\mathrm{i}} / \mathrm{W}_{\mathrm{i}}$ inner pore is valued 1 . This graph supports the process designer to determine an optimised die cavity design as well as the setting of the top die stroke for achieving the desired forming result.

\subsubsection{The parameter $R_{f}$}

A similar analysis method was used for examining the influence from $R_{f}$ (the radius of die fillet) to the formation of the tube inner pore. Fig.10. shows three results from the simulation, where all simulation conditions are the same except of variable $R_{f}$, which is $0.05 \mathrm{~mm}, 0.1 \mathrm{~mm}$ and $0.15 \mathrm{~mm}$ respectively. The other settings for the simulation are: micro-tube PP under $100^{\circ} \mathrm{C}$ forming 
temperature, $0.1 \mathrm{~mm}$ velocity, $R_{c}=0.35 \mathrm{~mm}$ and $h=0$. From the results it can be seen that the change of $R_{f}$ does not have a large impact to the shape of the tube inner pore, especially at the earlier forming stage when stroke is less than $0.4 \mathrm{~mm}$. With the increase of stroke, the difference of the three trend lines becomes more visible, which the largest fillet corner leads to the earliest reach of a ratio of 1 ; and the smallest fillet the last. It demonstrated that, for the hot embossing micro-tube forming, a larger radius of corner fillet produces lower resistance force on the tube material, which allows the material flow into die cavity easier.

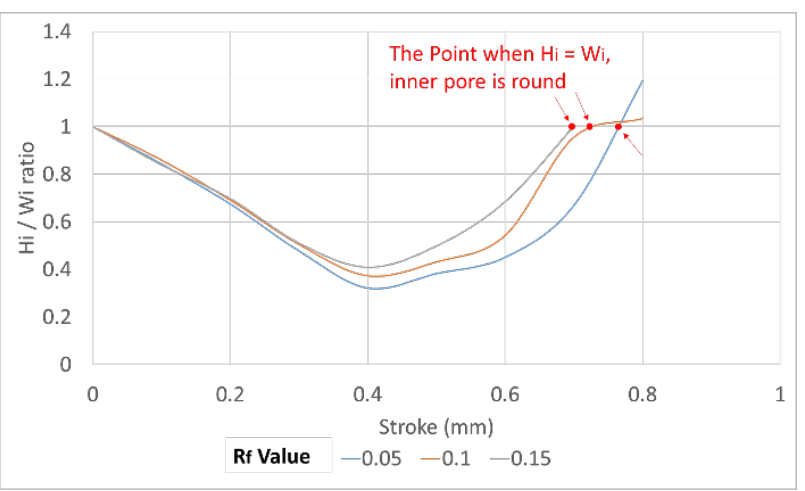

Fig. 10. Simulation result of $P P$ tube under $100^{\circ} \mathrm{C}\left(\right.$ change of $\left.R_{f}\right)$.

\subsubsection{The parameter $h$}

The $h$ represents the offset of the circle centre point for the die cavity, in other words, the depth of die cavity. The variation of $h$ applied in the simulation is $-0.1 \mathrm{~mm}, 0$ and $0.1 \mathrm{~mm}$ respectively. The results presented in Fig. 11 . shows the influence of the $h$ value to the shape of the tube inner pore size. As expected, the depth of the cavity also leads to different forming results of the tube inner pores. The deeper of die cavity leads to a shape transition of tube inner pore tend to vertical direction. When the forming goal is to form a reduced round inner pore, both $h=0$ or $0.1 \mathrm{~mm}$ are achievable. However, when the stroke setting is different, the achieved final inner pore sizes are also different. The inner pore size is around $0.35 \mathrm{~mm}$ when $h=$ $-0.1 \mathrm{~mm}$ and $0.1 \mathrm{~mm}$ when $h=0$.

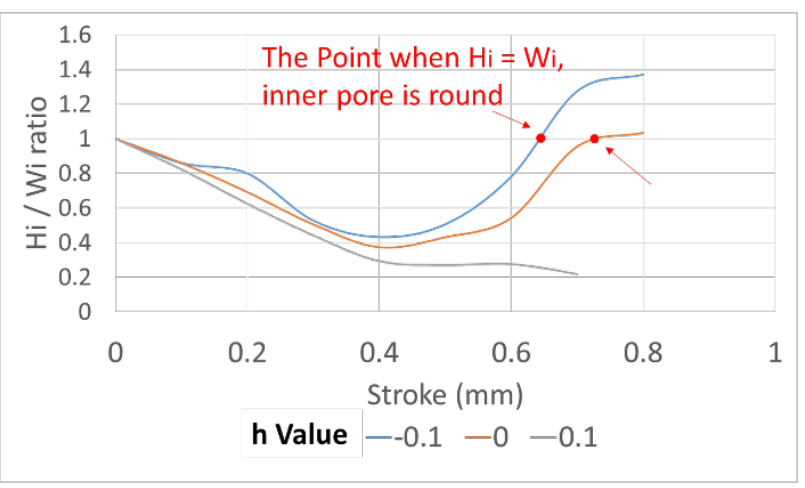

Fig. 11. Simulation result of PP tube under $100^{\circ} \mathrm{C}$ (change of $h$ ).

\subsection{The forming temperature}

The processing temperature is important for hot embossing as it influences the material flow and fusion bonding significantly. The viscosity of the polymer is directly responds to the applied temperature. Generally speaking, an elevated embossing temperature contributes to a better filling of die cavity, which results in increased forming quality. On the molecular level, when the temperature is raised, secondary bonding forces are diminished, so that the relative movement of adjacent chains is facilitated when a stress is applied. Compared to the hot embossing on a plane area for creating surface micro-structures, shaping a micro-tube requires lower temperature, because it can be characterised by the short flow-path of the polymer to the micro-cavity of the die insert [6]. The heating of the polymer should be maintained at a level to allow for the viscous short flow of material.

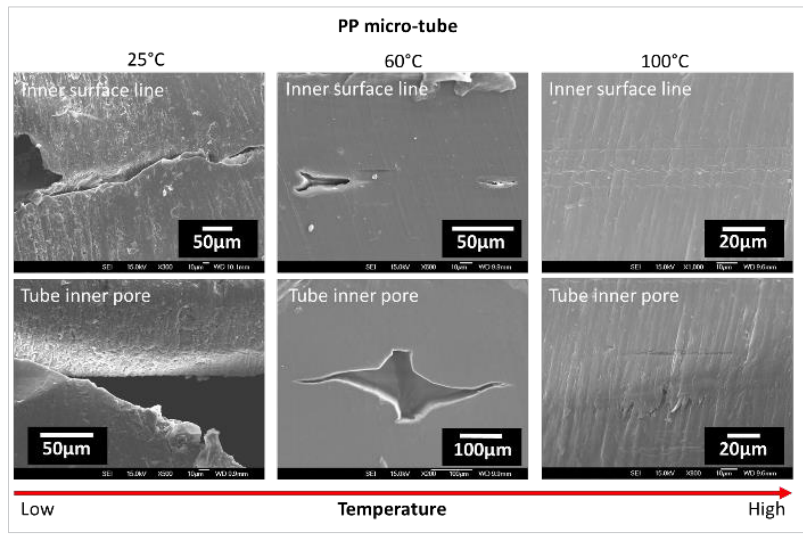

Fig. 12. The SEM images of PP tube formed under different temperature.

The Fig.12. present a group of SEM images for PP micro-tubes (cross-section view) formed under three levels of forming temperatures. Firstly, when the forming was carried out under room temperature, the material micro-structure was rough, especially near the junction between two contacting inner surfaces. By increasing the forming temperature, the material exhibits much smoother appearance. An oval inner pore has been produced and the inner surface boundary has clearly disappeared at $60^{\circ} \mathrm{C}$. When the forming temperature was raised to $100^{\circ} \mathrm{C}$, there is no sign of the surface line, which means the material on the inner boundary has melted and joined together. The molten material has filled the tube inner pore as well.

\subsection{The forming force}

Three kinds of forces may be acting on the micro-tube during the hot embossing process [7]. The applied force by movement from top die to bottom helps the polymer material flow into the die cavity. However, the other two forces, interface frictional force between the plastic material and the die cavity, also the surface tension force of the plastic material are resistant forces occurred during the process. Surface tension force becomes larger when the curvature of the die cavity becomes smaller. Increasing the process temperature (which lower the 
surface tension force), or increasing the applied force may alleviate this problem.

Since the changing of process temperature has been discussed in section 5.3, the discussion here is mainly focusing on the forming force in determining the shape of final product. The higher forming force is corresponding to a longer top die moving distance (the depth of embossing), which also means more vertical compression of the tube. The Fig.13 top three images show the geometry transformation of PP tube when the forming force changed from $2 \mathrm{KN}$ to $3 \mathrm{KN}$, by using the die cavity $\mathrm{R}_{\mathrm{c}}=0.45 \mathrm{~mm}$. The thickness of the exceed flash reduced from $0.22 \mathrm{~mm}$ to $0.17 \mathrm{~mm}$, along with the significant dimension change of $\mathrm{W}_{\mathrm{i}}$ and $\mathrm{H}_{\mathrm{i}}$. Likewise, the Fig.13. bottom shows the tube dimension change by using the die cavity $R_{c}=0.35 \mathrm{~mm}$. In addition, it is worth noting that the inner surface line of the micro-tube is obviously visible when the forming force is $2 \mathrm{KN}$; however, it disappeared when the forming force increased to $3 \mathrm{KN}$. It can be concluded that, the forming force provides energy for micro-tube deformation, as well as the energy for material inner molecular mobilisation and combination.
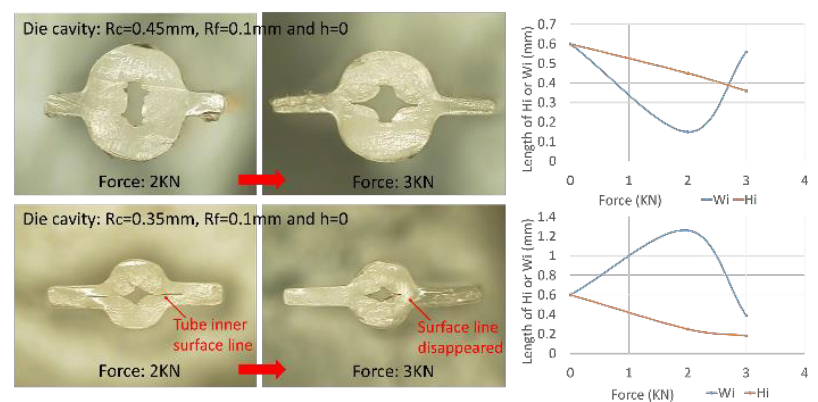

Fig. 13. PP micro-tube formed under room temperature and different forming force.

\subsection{The holding time}

Holding time is crucial to the formation of fully sealed tube inner interfaces bonding under an elevated temperature. As shown in Fig.14. the PP micro-tube was formed under the hot embossing parameters of $100^{\circ} \mathrm{C}$ forming temperature, $2 \mathrm{KN}$ force, $0.1 \mathrm{~mm} / \mathrm{s}$ forming velocity without hold time. As can be seen, the micro-tube presented a good deformation and formed a uniform shape of the outside profile and central pore. However, due to the viscosity of the polymer, material takes time to flow and fill all the undesired gaps. Hence, several small pores can be observed in the formed micro-tube, which are caused by the time limitation for the material to flow and stabilise the inner surface bonding.

Generally, longer holding time allows for the fusionbonded interfaces to settle down without separation after cooling. It is obvious a parameter which affects the production rate. To ensure good quality of the part to be produced, a longer holding-time is preferred. On the other hand, a longer hold time may affect the tool life due to the sustained hot-condition of the die/tool. An optimised holding time needs to balance the quality of the product and the tool life in the best interests of productivity.
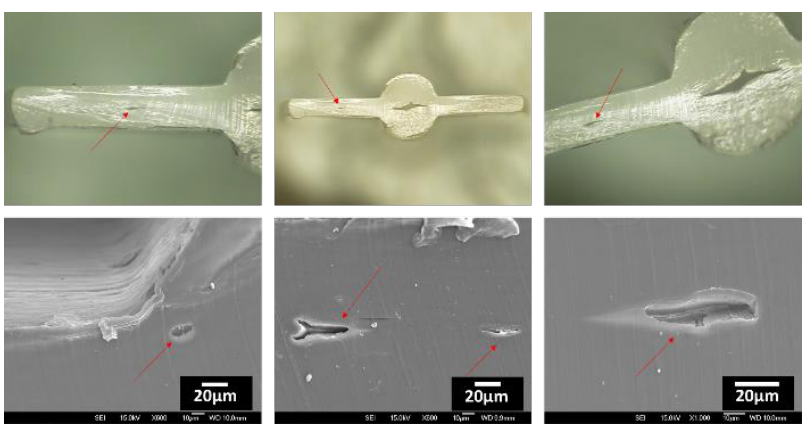

Fig. 14. The PP micro-tube formed under $100^{\circ} \mathrm{C}$ without holding time shows some small unfilled pores.

\section{Conclusion}

The hot embossing of PP micro-tube and its processing parameters are discussed in this paper. The results showed that PP is one preferable polymer for the desired hot embossing micro-tube forming. It is also shown that, the inner features (pores) with controllable sizes and shapes can be achieved with a proper die design and processing parameters set. It was further confirmed that the die geometry is a major factor in determining the material flow and, hence, the formation of the central pore. Other process variables, such as temperature, force and holding time, also play vital role for producing high quality end product.

Acknowledgement: Support from the European Commission for conducting research into the "A Process Chain and Equipment for Volume Production of Polymeric Micro-Tubular Components for Medical Device Applications (POLYTUBES)" (NMP2-SE-2009-229266) is acknowledged. Collaboration with all project partners in developing the hot-embossing process and the machine are particularly acknowledged.

\section{References}

1. A E. Gubera, M. Heckele, D. Herrmanna, A. Muslija, V. Saile, L. Eichhornb, T. Gietzelt, W. Hoffmann, P.C. Hauser, J. Tanyanyiwa, A. Gerlach, N. Gottschlich, G. Knebel. Chem. Eng. J. 101, Issues 13, 447-453 (2004)

2. Y. Qin, J. Zhao, G. Anyasodor, K.S. Hansen, I. Calderon, K. Konrad, C. Hartl, M. Arentoft, I.S. Chronakis, Micro-Manufacturing Engineering and Technology. 2nd ed. Oxford, 179-200 (2015)

3. J. Zhao, Y. Qin, A. Razali, A.L.K. Yip, Z. Fei, 7th International Conference on Micromanufacturing, 534-541 (2012)

4. J. Zhao, A.L.K. Yip, Y. Qin, A Razali, Z Fei. Trans. Nonferrous Met. Soc. China. 22, Supplement 2, s214-s221 (2012)

5. M. Worgull. Hot Embossing:Theory and Technology of Microreplication, 1st ed, Elsevier (2009)

6. M. Heckele, W. K. Schomburg. J. Micromech. Microeng. 14, Issue 3, R1-R14 (2004)

7. L. Lin, Y.T. Cheng, C.J. Chiu, Microsyst Technol, 4, 113-116 (1998) 